\title{
Processing relative locations in a natural space
}

\author{
RUTH H. MAKI \\ North Dakota State University, Fargo, North Dakota 58105
}

\begin{abstract}
Earlier experiments have shown that judging the relative locations of two-dimensional stimuli takes longer if those stimuli are horizontal than if they are vertical. If the terms east, west, north, and south are used, such effects may occur only in tasks where these words are synonymous with right, left, above, and below, and not in tasks where landmarks could be used. The present experiment was designed to determine whether east and west take longer than north and south in a more natural, three-dimensional space (locations on a college campus). College students responded to sentences describing the relative locations of buildings on their campus. East and west sentences took longer than north and south sentences, and locations close together took longer than locations farther apart. Thus, earlier results with two-dimensional stimuli were replicated in this more natural, three-dimensional space.
\end{abstract}

It is now well documented that adults have more difficulty in telling right from left than in telling above from below. Maki, Maki, and Marsh (1977) found this to be the case in several different tasks. In some experiments, they presented horizontally or vertically oriented pairs of symbols ( + and $o$ ) along with sentences of the form "(Symbol) is (locative) (symbol)." In one condition, the locatives were the spatial terms "right of," "left of," "above the," and "below the," and in another condition, the locatives were the compass terms "east of," "west of," "north of," and "south of." Subjects were to respond "true" if the locations described in the sentence matched the locations of the symbols and "false" if they did not. Reaction times (RTs) were longer for horizontally oriented symbols and locatives than for vertically oriented symbols and locatives. This difference was found whether the spatial terms or the compass terms were used. In other experiments, the relative locations of pairs of states of the United States were described and subjects were to indicate whether the described locations were "true" or "false." Again, east-west pairs of states took longer to respond to than did north-south pairs of states. In order to perform this task, subjects may have imagined a two-dimensional map of the United States. Thus, as in the task with symbols, east-west judgments would be synonymous with right-left judgments.

Loftus (1978) also found that the terms east and west produced longer RTs than the terms north and south in a task involving the comprehension of compass points. However, when the same task was performed with compass degrees rather than the compass terms,

I am grateful to Jennie Schuler for testing some of the subjects and to William S. Maki, Jr., for his helpful comments on the manuscript. Send reprint requests to Ruth H. Maki, Department of Psychology, North Dakota State University, Fargo, North Dakota 58105. there was no difference between the horizontal and vertical points. This suggests that the labels east and west are difficult relative to the labels north and south, but that perceptions of the locations themselves may not be differentially difficult. Maki, Grandy, and Hauge (1979) conducted a series of experiments designed to localize the stage of processing in which the difficulty with horizontal stimuli develops. They used the compass terms in some experiments and the spatial terms in others and found that the difficulty with horizontal stimuli lies in the labels themselves and not in the perception of the horizontal locations. Again, it did not seem to matter if the labels were right and left or east and west. Both sets were difficult relative to their respective vertical labels.

Whatever causes right and left to be difficult may also cause east and west to be difficult. Or it may be that the terms east and west are really not in themselves difficult, but that they were interpreted as right and left in all of the tasks described above. All of those tasks could be conceived of as involving two-dimensional location judgments in which east and west correspond to right and left, and north and south correspond to above and below. Thus the terms east and west may have been interpreted egocentrically, as right and left must be. Usually, however, the compass terms are not used in this egocentric sense because they are set by geographic conventions and are not dependent upon the direction a person is facing. In tasks in which the stimuli are not conceived of as two-dimensional, the terms east and west may be interpreted nonegocentrically, and the horizontal compass terms may be no more difficult than the vertical compass terms. On the other hand, if the words east and west really are difficult, then the specific task should be irrelevant; east and west should always take longer than north and south.

In order to test the generality of the east-west 
difficulty, students responded to sentences involving the locations of buildings on their college campus, North Dakota State University (NDSU). This space has been learned mainly by walking through it. Therefore, the representation of this real space may be somewhat different than the representation of a space that was learned via a two-dimensional display, as the locations of arbitrary symbols must be, and as the map of the United States probably is. Siegel and White (1975) reviewed evidence (e.g., Ladd, 1970; Shantz \& Watson, 1971) that shows that the quality of spatial representations is better when the space has been walked through than when it has not. This better representation may yield east-west judgments that are as good as north-south judgments. Not only does the campus involve a space that has been experienced, there is a second advantage of using the campus map. The maps of NDSU are printed with north and south to the right and left and west and east to the top and bottom. Thus, even if students do use the two-dimensional map to perform the task, east and west are not synonymous with right and left, but with up and down.

Because the difficulty with east and west may be accentuated when the terms are viewed egocentrically, two instructional conditions were used. In the "building" condition, subjects responded to the relative locations of two buildings. This task should encourage the use of landmarks and a nonegocentric approach. In the "me" condition, subjects were instructed to imagine themselves standing in a location on campus and to judge the compass direction of a building relative to that location. This should be more likely to encourage an egocentric view of the task than in the building condition. If egocentricity is important in the difficulty with east and west, then the me condition should produce a larger difference between east-west and northsouth RTs than should the building condition.

Distance between the two locations described in each sentence was also varied. Using states as stimuli, Maki et al. (1977) found that adjacent states took longer to respond to than nonadjacent states. They interpreted this as indicating that it is more difficult to determine the specific arrangement of stimuli when they are close together than when they are far apart; that is, the more similar the stimuli, the more difficult the discrimination. Potts (1972) demonstrated a similar effect with linear orderings. Subjects learned $A>B>C>D$ and then found it easier to say $A>D$ than to say $A>B$. Whereas this type of effect may occur with linear orderings and with locations learned in two-dimensional space (e.g., United States map), a different effect may occur for a space that has been learned by walking through it. Subjects may tend to imagine themselves going from one point to another in order to perform the RT task. Kosslyn, Ball, and Reiser (1978) have shown that response time increases with the distance that must be scanned on a mental image. Therefore, if subjects scan mental images of the campus, far locations should take longer than near locations. The present experiment was designed to test this, as well as to see whether the difficulty with east-west stimuli would occur with this more natural space.

\section{METHOD}

Four different maps of the NDSU campus were prepared. Each map included the locations and names of eight campus buildings. Four of these were in a relatively straight east-west line and four were in a relatively straight north-south line, such that the east-west and north-south buildings formed a cross. Subjects studied one of the four maps for $30 \mathrm{sec}$ and then they were asked to fill in the names of the buildings and the compass points on a map that marked the locations of the buildings. Any errors were pointed out to the subject, and all subjects studied the map for another $30 \mathrm{sec}$. A second test was given, in which the names of the buildings and the compass points were written. If the subject was correct, the map was not presented for study again; if the subject was incorrect, the map was presented for study and the subject was tested until the building names and compass points had been written correctly. Then, the two groups of subjects were treated differently. The building group was simply given a blank map again and asked to fill in the names of the buildings and the compass points. They were asked to pay specific attention to the relative locations of the buildings in terms of the compass points while filling out the map. The me group was shown a location on the map (the center of the cross) and asked to imagine that they were standing at that location. They were instructed to fill in the building names and the compass points and to pay specific attention to the location of each building relative to where they were to imagine themselves standing. If the subject was correct in filling in the map, this portion of the experiment was ended. If an error was made, more study of the map was given and testing continued until the map was filled in correctly.

A RT task was then presented. In the building condition, sentences of the form "(Building) is (locative) (another building)" were presented with "east of," "west of," "north of," and "south of" as the locatives. In the me condition, sentences of the form "(Building) is (locative) me" were presented with the same four compass points as locatives. Half of the trials were east-west trials and half were north-south trials. On the near trials, the building name that served as the subject of the sentence was either adjacent to the building name that served as the predicate of the sentence or adjacent to the location at which the subject was standing. On the other half of the trials, the two buildings or the building and the subject's location were separated by at least one other building; these were called far trials. For each subject, half of the trials were true and half were false. On all false trials, the incorrect locative was from the same orientation as the correct locative; that is, if the correct locative was south, the incorrect locative was north, not east or west. The design was a 2 by 2 by 2 by 2 mixed factorial with building vs. me condition as a between-subjects variable and orientation, distance, and truth as within-subjects variables.

Sentences were presented on a Lear-Siegler ADM3A terminal controlled by an Automated Data Systems 1800E computer. Each trial began with the word PRESS displayed on the terminal. At this time, half of the subjects pressed a center button on the response console with the index finger of their right hands, and half pressed with the index finger of their left hands. After the button had been depressed for $500 \mathrm{msec}$, a sentence was displayed on the screen. Subjects were instructed to press one of two side buttons if the sentence was true and the other side button if it was false. The two side buttons were 
arranged at a 45-deg angle with respect to the center button for half of the subjects and at a 315-deg angle for the other half of the subjects. Thus, the response button arrangement was neither horizontal nor vertical with respect to the subjects. Following the response, there was an intertrial interval of $2 \mathrm{sec}$ before the next trial was begun.

A total of 30 subjects were tested in the experiment. Twelve were randomly assigned to the me condition. The other 18 subjects were tested in the building condition, but the data from 6 subjects could not be used because they made more than $50 \%$ errors in some conditions. Thus, the data from a total of 24 subjects were actually used in the experiment.

\section{RESULTS AND DISCUSSION}

The RT data are presented in Table 1. A mixed-design analysis of variance was conducted on the RT data. The me condition produced faster RTs than did the building condition $[\mathrm{F}(1,22)=25.94, \mathrm{MSe}=3.637, \mathrm{p}<.05$ (the significance level used for all statistical tests)]. Northsouth locations were faster than east-west locations $[\mathrm{F}(1,22)=10.57, \mathrm{MSe}=.218]$, true statements were faster than false statements $[\mathrm{F}(1,22)=38.21, \mathrm{MSe}=$ $.031]$, and far locations were faster than near locations $[\mathrm{F}(1,22)=55.71, \mathrm{MSe}=.160]$. Distance interacted with condition, with a larger distance effect in the building condition than in the me condition $[F(1,22)=14.91$, $\mathrm{MSe}=.160]$. This probably occurred because the far distances were actually greater in the building condition than in the me condition.

Proportion errors are also presented in Table 1. An analysis of variance on these data indicated that east-west relationships produced more errors than north-south relationships $[\mathrm{F}(1,22)=7.96, \mathrm{MSe}=.004]$. There was also an interaction between condition, distance, and truth $[\mathrm{F}(1,22)=4.67, \mathrm{MSe}=.002]$. The interaction apparently occurred because the difference in error rates in the near and far conditions was smaller in the me-false condition than in the me-true condition, but in the building condition the distance effect tended to be smaller with true statements.

Although a fairly large number of subjects were lost in this experiment due to high error rates, the reasons for the loss are consistent with the final outcome of the experiment. All lost subjects were in the building condition, which proved to be the more difficult condition for those subjects whose data could be used.
All of the subjects who were lost made more errors on east-west than on north-south statements. East-west RTs were slower than north-south RTs for those subjects whose data were used. If anything, then, the large loss of subjects may have made the effects of the me vs. building conditions and the effects of orientation smaller than they would have been had those subjects not been lost.

Consistent with the findings of Maki et al. (1977), judgments of near stimuli took longer than judgments of far stimuli. Apparently, near stimuli are more difficult than far stimuli when relative locations are judged whether they involve distances that have been walked, as in the present experiment, or two-dimensional distances, as in earlier experiments. Because far stimuli were faster than near stimuli, subjects must not have scanned a mental image as the subjects of Kosslyn et al. (1978) were instructed to do. For the present experiment to be analogous to the Kosslyn et al. task, subjects would have been instructed to imagine going from one building to another and asked to decide whether they passed a third building en route. Presumably, such a task would yield longer RTs for longer distances. The present task is more a discrimination task, in which subjects must decide how the location of one building differs from the location of another. The task is apparently not accomplished by scanning the distance between the two locations. Because the findings in the present experiment are similar to those found in linear ordering tasks, locational judgments may be performed in the same manner as the linear ordering tasks. Abstract locational codes may be generated and then compared.

As has been found in earlier research with twodimensional locational stimuli, east-west locations were more difficult than north-south locations. The me condition was easier than the building condition, probably because the location of "me" was constant. However, condition did not interact with orientation, suggesting that attempting to make the task more egocentric had no effect on the size of the east-west difficulty. The results of this experiment suggest that the words east and west really are inherently more difficult than the words north and south and the exact nature of the task in which they are used is irrelevant. Whatever causes the difficulty people have in responding

Table 1

Mean Reaction Times (RT) in Seconds and Proportion Errors (E) in Judgments of Relative Locations

\begin{tabular}{|c|c|c|c|c|c|c|c|c|c|c|c|c|c|c|c|c|}
\hline & \multicolumn{8}{|c|}{ Building Condition } & \multicolumn{8}{|c|}{ Me Condition } \\
\hline & \multicolumn{4}{|c|}{ Near } & \multicolumn{4}{|c|}{ Far } & \multicolumn{4}{|c|}{ Near } & \multicolumn{4}{|c|}{ Far } \\
\hline & \multicolumn{2}{|c|}{ East-West } & \multicolumn{2}{|c|}{ North-South } & \multicolumn{2}{|c|}{ East-West } & \multicolumn{2}{|c|}{ North-South } & \multicolumn{2}{|c|}{ East-West } & \multicolumn{2}{|c|}{ North-South } & \multicolumn{2}{|c|}{ East-West } & \multicolumn{2}{|c|}{ North-South } \\
\hline & RT & $\mathrm{E}$ & RT & E & RT & E & RT & $\mathrm{E}$ & RT & $\mathrm{E}$ & RT & $\mathrm{E}$ & RT & $\mathrm{E}$ & RT & $\mathrm{E}$ \\
\hline $\begin{array}{l}\text { True } \\
\text { False } \\
\text { Mean RT }\end{array}$ & $\begin{array}{l}3.676 \\
3.716 \\
3.696\end{array}$ & $\begin{array}{l}.096 \\
.104\end{array}$ & $\begin{array}{l}3.238 \\
3.404 \\
3.321\end{array}$ & $\begin{array}{l}.058 \\
.067\end{array}$ & $\begin{array}{l}2.858 \\
3.132 \\
2.995\end{array}$ & $\begin{array}{l}.083 \\
.046\end{array}$ & $\begin{array}{l}2.602 \\
2.828 \\
2.715\end{array}$ & $\begin{array}{l}.062 \\
.046\end{array}$ & $\begin{array}{l}1.914 \\
1.999 \\
1.956\end{array}$ & $\begin{array}{l}.083 \\
.046\end{array}$ & $\begin{array}{l}1.740 \\
1.882 \\
1.811\end{array}$ & $\begin{array}{l}.042 \\
.021\end{array}$ & $\begin{array}{l}1.645 \\
1.783 \\
1.714\end{array}$ & $\begin{array}{l}.042 \\
.050\end{array}$ & $\begin{array}{l}1.544 \\
1.731 \\
1.638\end{array}$ & $\begin{array}{l}.029 \\
.012\end{array}$ \\
\hline
\end{tabular}


to the words right and left may also cause similar difficulty with the words east and west.

\section{REFERENCES}

Kosslyn, S. M., BALL, T. M., \& Reiser, B. J. Visual images preserve metric spatial information: Evidence from studies of image scanning. Journal of Experimental Psychology: Human Perception and Performance, 1978, 4, 47-60.

LADD, F. C. Black youths view their environment: Neighborhood maps. Environment and Behavior, 1970, 2, 64-79.

Loftus, G. R. Comprehending compass directions. Memory \& Cognition, 1978, 6, 216-422.

Maki, R. H., Grandy, C., \& Hauge, G. Why is telling right from left more difficult than telling above from below? Journal of
Experimental Psychology: Human Perception and Performance, $1979,5,52-67$.

MAKI, R. H., MAKI, W. S., \& MARSh, L. G. Processing locational and orientational information. Memory \& Cognition, 1977, 5, 602-612.

PotTs, G. R. Information processing strategies used in the encoding of linear orderings. Journal of Verbal Learning and Verbal Behavior, 1972, 11, 727-740.

Shantz, C. U., \& Watson, J. S. Spatial abilities and spatial egocentrism in the young child. Child Development, 1971, 42, 171-181.

Siegel, A. W., \& White, S. H. The development of spatial representations of large-scale environments. In H. W. Reese (Eds.), Advances in child-development and behavior (Vol. 10). New York: Academic Press, 1975.

(Received for publication March 26, 1979.) 